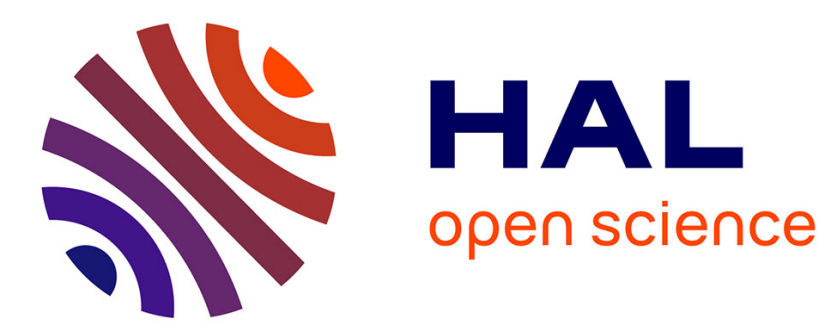

\title{
Relationship between tree morphology and growth stress in mature European beech stands
}

Delphine Jullien, Robert Widmann, Caroline Loup, Bernard Thibaut

\section{To cite this version:}

Delphine Jullien, Robert Widmann, Caroline Loup, Bernard Thibaut. Relationship between tree morphology and growth stress in mature European beech stands. Annals of Forest Science, 2013, 70 (2), pp.133-142. 10.1007/s13595-012-0247-7 . hal-00804664

\section{HAL Id: hal-00804664 https://hal.science/hal-00804664}

Submitted on 26 Mar 2013

HAL is a multi-disciplinary open access archive for the deposit and dissemination of scientific research documents, whether they are published or not. The documents may come from teaching and research institutions in France or abroad, or from public or private research centers.
L'archive ouverte pluridisciplinaire HAL, est destinée au dépôt et à la diffusion de documents scientifiques de niveau recherche, publiés ou non, émanant des établissements d'enseignement et de recherche français ou étrangers, des laboratoires publics ou privés. 
$1 \quad$ DOI: $10.1007 / \mathrm{s} 13595-012-0247-7$

2 Relationship between tree morphology and growth

3 stress in mature European beech stands.

4 Delphine JULLIEN* ${ }^{(\mathrm{a})}$, Robert WIDMANN ${ }^{(\mathrm{b})}$, Caroline LOUP $^{(\mathrm{a})}$, Bernard THIBAUT $^{(\mathrm{a})}$

5 (a) LMGC, UMR 5508 CNRS - Université Montpellier 2, France

(b) EMPA, Materials Science \& Technology, Dübendorf, Switzerland

7

*Delphine JULLIEN, LMGC, UMR 5508 CNRS - Université Montpellier 2, Place Eugène Bataillon, CC 048, 34095 Montpellier Cedex 5, France.

10

Tel: +33-467143431 - Fax: +33-467144792

11 Email: Delphine.Jullien-Pierre@univ-montp2.fr 
13 Aims: In European Beech (Fagus sylvatica L.) large growth stresses lead to severe log end

14 splitting that devaluate beech timber. Our study aimed at detecting relationships between growth

15 stress and some morphology parameters in trees.

16 Methods: Growth stress indicators were recorded for 440 mature trees in 9 stands from 5 European

17 countries, together with morphology parameters.

18 Results: Most trees displayed an uneven distribution of growth stress around the trunk. Moreover,

19 growth stress intensity varied largely between individual trees. Geometry of the trunk was a poor

20 predictor of growth stress intensity. Crown asymmetry resulted in a larger stress dissymmetry

21 within trees. Trunk inclination was not correlated to mean or tension stress, contrary to what is

22 usually found in younger trees. In the case of small inclination, growth stress was close to

23 expected from biomechanics of restoring verticality. Trees exhibiting a larger inclination probably

24 evolved a different mechanical solution: a rather large crown, lower tree slenderness and a

25 sufficient asymmetry in growth stress as to prevent a higher inclination due to growth.

26 Conclusion: A large slenderness is the best accurate predictor of a large growth stress, although

27 variations in the ratio Height/DBH explained only $10 \%$ of the variability of growth stress. A large

28 crown surface was the best predictor of a low level of growth stress. A large spacing between trees

29 seems a good solution to lower the risk of growth stress in mature Beech.

30 (iii) Introduction

31 European Beech (Fagus sylvatica L.) is an important tree species, with a rather large distribution 32 in western and central Europe (Alvarez-Gonzalez et al. 2010). Besides firewood, beech is mainly used for furniture, packaging, plywood and decorative veneer.

34 Two main defects in standing trees have important consequences on timber value in industry 35 (Knoke et al. 2006): red heart colour (Liu et al. 2005) and high level of growth stresses leading to $36 \log$ end splitting in veneer industry and board warping in sawmills (Saurat and Gueneau 1976; 37 Archer 1986; Kübler 1987). 
Three main types of forest management are applied to beech stands in Europe: pure coppice for

39 firewood, high stand, even aged forest, for sawing and veneer industries, coppice-with-standards:

40 middle forest combining coppice and mature trees, for mixed uses. Sometimes coppice and

41 coppice-with-standards were transformed in high stand forest more than one century ago.

42 Growth stresses are always present in trees, (Archer 1986; Kübler 1987; Fournier et al. 1994a;

43 Thibaut and Gril 2003; Jullien and Gril 1996 and 2008).

44 Strictly speaking, the term growth stress should describe the whole stress field in a trunk resulting

45 from tree growth. On one side there are the stresses accumulated as a result of self weight

46 increasing, called "support stresses". On the other side there are the stresses resulting from the pre-

47 stressing phenomena occurring in each new wood layer at the end of the fibre differentiation

48 process, during cell wall lignifications, called "maturation stresses" (Fournier et al 1994a). Usually

49 this stress field is described on a transverse section of the bottom of the trunk, where it is supposed

50 to be the highest.

51 Support stress field in a continuously growing structure is not usual. Let us consider that a beech

52 tree can be assimilated to a vertical column, perfectly cylindrical which dimensions are $\mathrm{R}$ and $\mathrm{H}$,

53 radius and height of the column (assuming that the weight of branches compensate the loss of stem

54 diameter as we go from bottom to top of the tree). A simple rule of allometry is used to link $h(t)$

55 and $\mathrm{r}(\mathrm{t})$ all along tree growth: $\mathrm{h}(\mathrm{r})=\mathrm{H}(\mathrm{r} / \mathrm{R})^{2 / 3}$.

56 If the column is built classically by piling successive elements of radius $\mathrm{R}$ and thickness $\mathrm{T}$, until

57 reaching the height $\mathrm{H}$ (Fig. 1), there will be a uniform compressive stress field all over the section

58 with the stress magnitude: $\sigma_{0}=\rho g H$, where $\rho$ is the density of the material $\left(\rho=1000 \mathrm{~kg} / \mathrm{m}^{3}\right.$ for

59 green beech wood), $\mathrm{g}$ is the gravitational field, $\left(\mathrm{g}=10 \mathrm{~m} / \mathrm{s}^{2}\right)$. For a $30 \mathrm{~m}$ height column made of

60 green wood, $\sigma_{0}$ will have a uniform low value of $0,3 \mathrm{MPa}$.

61 In a growing column, each new wood layer starts to be loaded only after it is formed, so we have an incremental problem. From the moment that it has been produced at the distance $r$ from the pith until the final growth of the tree at radius $\mathrm{R}$, the wood layer situated at $\mathrm{r}$ position will support an increase of compressive stress due to each new layer deposition. So the final stress will be highest near the pith (the first growth ring will support all the successive increase of compressive stress 

due to growth). On the contrary, the last growth ring, being just elaborated will not support any stress from what happen before its birth.

In the studied case, the solution of the incremental calculation of stress level at each $r$ position in the bottom section is very simple: $\left.\sigma(\mathrm{r})=-4 \sigma_{0}\left(1-(\mathrm{r} / \mathrm{R})^{2 / 3}\right)\right)$, where $\sigma_{0}=\rho g H$. In this case, compressive stress is zero at periphery and 4 times greater than the uniform case value $\sigma_{0}$ (Fig. 1). This maximum value is only $1.2 \mathrm{MPa}$ anyway, which means that compressive support stress is very low compared to wood resistance to axial compression (around $50 \mathrm{MPa}$ for green beech wood).

The same remark can be applied to a cantilever beam. For a classic beam anchored at one end after the making of the beam, there is maximum tensile stress $+\sigma_{\mathrm{m}}$ at the top of the beam, at anchorage level, and a maximum compressive stress $-\sigma_{\mathrm{m}}$ at the bottom (Fig. 2).

For a growing anchored beam, the incremental solution is very different, because, again, the last growth ring should have a zero stress all around the beam. The calculus shows that the tensile and compressive stresses are maximum not far from the pith, with a much higher level than $\sigma_{\mathrm{m}}$ (Fig. 2).

For a slightly inclined column, the support stress field at bottom is the sum of the compressive stress field calculated for a vertical beam and the flexure stress field obtained by multiplying the values for a horizontally anchored beam by the beam inclination (TI) in $\%$. For TI $=5 \%$, the compressive stress field is negligible as compared to the flexure one (Fig. 3).

But we know that the growth ring, just produced at distance $r$ from the pith is in fact pre-stressed in tension with a rather high value ( $\sigma_{\text {mat }}=10 \mathrm{MPa}$ for example in this case). This pre-stressing leads to a global force $F_{\text {mat }}$ on this ring that values $2 \pi r(d r) \sigma_{\text {mat }}$, $d r$ being the thickness of the incremental new ring produced at $\mathrm{r}$ position. In order to counterbalance this force $\mathrm{F}_{\text {mat }}$ there will appear a uniform compressive stress $\sigma_{\text {comp }}$ in the existing core which radius is $r: \sigma_{\text {comp }}=F_{\text {mat }} /\left(\pi r^{2}\right)$. The calculus of this increment from the first ring to the periphery gives the classical "Kubler model" of growth stress which we call the maturation stress field.

At the end, the growth stress field is the sum of these 3 distributions (Compression + Flexure + Maturation) (Fig. 3). 
94 For a vertical, straight, equilibrated tree, the growth stress field is practically equal to the

\section{4 (iv) Materials and methods} the maturation stress in the last ring. for old mature trees with big diameters use. growth stress in beech.

\section{Stand selection} maturation stress field. For more or less inclined or unbalanced trees, the stress field is no more symmetrical. Any dissymmetry in maturation stress between two sides of the trunk will also change a lot the stress field (Fournier et al 1994a) but the stress value at tree periphery is always

So it should be kept in mind that measurement of maturation strains at tree periphery is just a picture of the present pre-stressing action of the last grown wood in the tree.

Previously inclined young trees in the process of vertical recovery have trunks curved upwards with tension wood on the upper part of the trunk (Almeras et al 2005). But this might not be true

Because maturation strain is the driving phenomena leading to very important problems in forest industries using beech wood (accidents due to log end splitting, severe loss in sawmills or veneer industry), it is of uttermost importance to try and understand what are the main factors influencing the level of maturation strains in beech tree, in order to improve both forest management and log

The objective of this paper is to examine whether growth stress level in beech could be anticipated from observations on standing trees, as trunk inclination and sinuosity, crown size, position and symmetry or tree slenderness. Moreover using plots from very different silvicultural treatment was a way to confirm on a broad scale the former results on the influence of forest management on

The stands have been selected to emphasize similarities and differences between the growth stress levels of trees under well-defined growing conditions. In total nine stands in the following five countries were used for the study: Austria, Switzerland, Germany, Denmark and France. 
119 Six stands are classical high stand forest, the following list contains stand designator, site, altitude

120 and average tree age:

121 - Aa $=$ Purkersdorf, Austria (alt. $400 \mathrm{~m}$, about150 years)

$122 \quad-\mathrm{Ab}=30 \mathrm{~km}$ of Salzburg, (alt. 900m, about 140 years)

123 - Dk = Ravnsholte, Denmark (alt.120m, about 120 years)

$124 \quad$ - Fa = Moyeuvre, France (alt. 320 m, about 110 years)

125 - Sa = Baden, Switzerland (alt. $450 \mathrm{~m}$, about 110 years)

$126 \quad$ - $\mathrm{Sb}=$ Le Fahy, Switzerland (alt. 500m, about 170 years)

127 Two stands are middle forest type management:

$128 \quad \mathrm{Fb}=$ Ecouves, France (alt. 200m, about 150 years)

$129 \quad$ - Fc $=$ Sassey, France (alt. $250 \mathrm{~m}$, about 130 years)

130 The trees of the German stand were first grown under a middle forest management system. The

131 treatment of this stand was later on given up and replaced by a high forest management system.

132 - $\mathrm{G}=$ Schefflenz, Germany (alt. 270m, about 190 years)

\section{Tree selection}

134 Out of the nine stands, 50 trees per stand were selected for detailed investigations. Trees were 135 chosen with a mean diameter at breast height of at least $45 \mathrm{~cm}$ and without branches up to a height 136 of at least 4,5 meters. Trees with obvious damages of the bark, wavy grain or rotten trunks were 137 not selected.

\section{Tree morphology}

139 The total height of the tree $(H)$ and the diameter at breast height $(D B H)$ were systematically 140 measured. Slenderness was calculated as the ratio between total height and diameter at breast 141 height $(H / D B H)$. The trunk inclination at the base of the tree $(T I)$ was estimated by measuring the 142 distance between the trunk and a 2 meters long "plumb line".

143 Eight sticks were placed vertically below eight points describing the crown periphery. The 144 position of the eight sticks was registered by their orientation in relation to the North direction and 
their distance to the trunk of the referenced tree. The area of the crown projection $(C S)$ was deduced from these measurements, as well as the geometrical centre of the crown projection which is very similar to the projection of crown centre of gravity (Barbacci et al 2009). The distance between the centre of the crown projection and the trunk $(C E)$ gives an indication of crown eccentricity related to tree base. Photos and drawings of most of the trees have been made in two different directions in order to show trunk inclination and curvature, branches orientation or abundance, fork presence and disposition.

Crown shapes were visually separated in 2 classes: "symmetrical" $(S)$ and "asymmetrical" $(A S)$. For trunk shape four classes have been defined: straight (more or less inclined) trunk (T1), trunk curved at base (T2), trunk with one big curve (T3), sinuous trunk with more than one curve (T4) (Tab. 1).

Table 1 indicates the number of trees (with a complete set of measurement) for each stand in each category of crown and trunk shape. The symmetric crown category is a little less represented than the dissymmetric one (194 compared to 246). The trunk category $T 1$ corresponding to straight trunks is much more represented than the sinuous trunks T2, T3 and T4 (251 compared to 48, 81, $60)$.

\section{Growth stress description}

Eight values of growth stress indicator were measured on stem periphery, at breast height. Each indicator is obtained by the single-hole method (Fournier et al. 1994b; Yang et al. 2005). It consists in debarking a circumferential part of the trunk, fixing pins to the wood at two points which are aligned in the longitudinal direction of the trunk at a $45 \mathrm{~mm}$ distance, drilling a $20 \mathrm{~mm}$ diameter hole between the two pins and measuring the relative displacement of the pins due to the drilling. This displacement, being referred to as growth stress indicator $(G S I)$ in $\mu \mathrm{m}$ is positive each time the growth stress is a tensile stress (a negative value would indicate compression wood). GSI value is proportional to the local longitudinal maturation strain $\left(\varepsilon_{\mathrm{M}}\right)$ through formula (1) (Baillères 1994).

$$
\varepsilon_{\mathrm{M}}=12.9 \cdot 10^{-6} \cdot G S I
$$


173 longitudinal modulus of elasticity of beech wood in the measurement zone.

$$
\sigma_{\mathrm{G}}=\varepsilon_{\mathrm{M}} \cdot E
$$

175 For angiosperms, $E$ does not vary so much between tension and normal wood (Alméras et al.

176 2005). So GSI is a good proxy of growth stress at stem periphery of one tree. Between beech trees,

$177 E$ can vary at a maximum by a factor of two, thus strictly speaking, GSI is a better proxy for 178 maturation strain than for maturation stress.

179 The GSI was measured at eight points that were evenly distributed along the circumference of each

180 trunk and the position of the points was defined in reference to the north direction as it is shown in

181 (Fig. 4).

182 The minimum (Min), maximum (Max), mean (Mean) value of the 8 indicators per tree and the 183 difference between the maximum and the minimum values (Range = Max-Min) were calculated for 184 each tree in order to obtain 4 growth stress tree parameters for the analysis.

\section{$185 \quad$ (v) Results}

In table 2 an overview of all relevant GSI and dendrometric parameters for all trees is given.

188 Variations are rather low for $D B H$, height and tree slenderness but very high for crown area, 189 crown off-centering and trunk inclination, and high for all GSI tree parameters.

190 The distribution of all GSI measurements (8 per tree, Online Resource 1) is classical with a clear 191 peak around $45 \mu \mathrm{m}(0,058 \%$ strain value $)$, and a long trail for tension wood zones values. It is 192 comparable to what was found for other hardwood species (Fournier et al. 1994; Alméras et al. 193 2005).

194 There was a clear correlation between the direction of leaning of a given tree and the direction of 195 the maximum stress measurement at the circumference (Becker and Beimgraben 2001). 
Assuming a mean value of $12 \mathrm{GPa}$ for beech green wood MOE, the mean growth stress value $\sigma_{\mathrm{C}}$ over all trees is $9.64 \mathrm{MPa}$.

The differences between low stressed and highly stressed trees are important (more than a 4 times ratio between the 5\% higher and lower percentile) for all the GSI tree parameters (Fig. 5). $45 \%$ of the trees have a range of growth stress higher or equal to $15 \mathrm{MPa}$, and only $15 \%$ lower than $8 \mathrm{MPa}$ (around $50 \mu \mathrm{m}$ for $G S I$ value).

\section{Mean results by stand, trunk and crown type}

In Online Resource 2 and 3 the mean values of GSI and morphological parameters measured on standing trees, by stand, trunk and crown type are shown.

Differences are much higher between stands than between trunk or crown types (Tab. 3). There are significant differences between stands at $0.1 \%$ level for all GSI and dendrometrical parameters. Trunk type never gives significant difference except for trunk inclination. Crown asymmetry leads to significant differences for all dendrometrical parameters (higher for $D B H$, crown parameters and trunk inclination), but only for Max-Min GSI (at 1\% level).

\section{Correlation between parameters}

In Table 4 the coefficients of correlation for measured growth stress and tree morphology data for all straight trees (trunk type 1, 251 trees) are indicated. However, the results are fairly identical if these values for all 440 trees (inclined and not inclined) are being correlated.

There are strong significant positive correlations among GSI parameters (except for Min and Range) and also among tree dimension parameters ( $D B H$, Height, crown surface). Parameters expressing the disequilibrium of the tree (trunk inclination and crown eccentricity) are not significantly related to tree dimension except for trunk inclination and total height. All GSI parameters have strong significant correlation at the $0.1 \%$ level with slenderness (always positive) and crown surface (always negative). The influence of $D B H$ is very similar to that of crown surface and height to slenderness (same sign, but lower level of significance if any). It should be noted that slenderness of trees explains only $10 \%$ of GSI max variability (Fig. 6). 


\section{4 (vi) Discussion}

Ideally, if equilibrated during its whole life, a straight vertical tree is expected to have an equilibrated level of growth stress along the circumference of its trunk. However, for the trees in this study this was only the case for rather few trees. Most of the trees have a marked asymmetry of GSI corresponding to a response to a mechanical disequilibrium of the tree (mainly tree inclination).

Each time there is a need for a strong mechanical reaction, e.g. aiming at changing trunk geometry in order to restore verticality after some accidental leaning the cambium will produce tension wood (Coutand et al. 2007; Jourez et al. 2003; Alméras et al. 2005 and 2009; Wilson et al. 1979 and 1996; Moulia and Fournier 2009). The tension wood is being produced on one side of the trunk, usually on an angular section ranging from $90^{\circ}$ to $120^{\circ}$. When tension wood occurrence lasts long enough at the same position of the trunk, a tension wood growth layer of a sufficient dimension will develop with the result that the tensile force is much higher at this position of the trunk circumference. This introduces a flexure moment and a change in curvature of the trunk results. The tension wood is positioned on the concave side of the curvature (i.e. on the upper side for an inclined tree restoring its verticality).

\section{Maturation stresses}

Ranging the 8 GSI values from the smallest (min) to the highest $(\max )$ in each tree, leads to a typical distribution in two parts (Fig. 7). The four lower values grow linearly with a rather low slope while the four higher ones grow linearly with a slope nearly three times higher. The first part corresponds globally to the sector without any tension wood (opposite wood OW). The second 
part corresponds to the peak of growth stress where the presence of tension wood TW can be

247 dominant.

248 Max-Min GSI is used as a mechanical indicator for restoration of verticality. Under the 249 consideration that the position of GSI max is very close to the peak of high tension wood sector 250 the difference between this GSI max and the GSI value found on the opposite position (Tension251 Opposite GSI) can be calculated. As shown in the relationship between Max-Min GSI on one side, Tension-Opposite GSI on the other side (Fig. 8) the two values are very similar and very strongly correlated. The width of the strip close to bisector line results from the fact that the "true" peak and the "true" opposite sides can be at plus or minus $45^{\circ}$ from what was chosen. Trees strongly outside of the high correlation strip are those with unusual growth stress profile (Fournier et al 2004a) for example with two tension peaks.

Globally GSI max is a good proxy for tensile side while GSI min is a valuable proxy for the opposite side.

\section{Tree morphology and growth stresses}

There are no significant differences between curved and straight trees for growth stresses. This is rather opposite to what is usually found for small diameter trees. It could be suspected that for big trees, highly stressed straight vertical ones are at the end of their verticality restoration phase. It is commonly believed that trunk inclination should be a factor that positively influences growth stress (Wilson et al. 1996), because of tension wood occurrence in order to restore verticality. For the mature beech trees of the present study, there are significant negative correlations between trunk inclination, mean and minimum GSI values (for straight trees as well as for all of them). For a better assessment of this relationship, the straight trees were put into classes of different inclination (Online Resource 6). All classes gather roughly 20 trees except 80 trees for the first class with zero inclination. 
272 GSI for opposite wood (GSI min) is slowly decreasing when trunk inclination grows until $2.5 \%$.

273 Then it suddenly drops and continues to slowly decrease after. The same general pattern is shown

274 for GSI mean. GSI max begins to grow until $2.5 \%$ inclination, but decreases rather abruptly after

275 that and stays more or less flat until the highest tree leaning, with similar values as vertical trees.

276 GSI Max-Min, is lower for vertical trees but it stays more or less stable in inclined trees because

277 the decrease in GSI min compensate the decrease in GSI max. Looking at dendrometrical

278 parameters, trees with inclination over $2.5 \%$ have low H/DBH (below 55) and high crown surface.

279 Based on the results of big beech trees, it seems that a threshold for trunk inclination around $2.5 \%$

280 exists. Above this value, all GSI values decrease strongly, except for GSI max-min that keeps

281 more or less constant at a value approximately $20 \%$ higher than for vertical trees. Straight trees

282 exhibiting high trunk inclination do not use very high maximum GSI values on the tensile side but

283 rather low values on the opposite side so they keep a sufficient asymmetry in GSI in order to

284 prevent more tree leaning. They have bigger crowns and it should be looked more closely whether

285 this crown development contributes to some limitation in the disequilibrium of the tree.

286 Finally, for old mature trees, morphological traits as inclination, straightness or crown symmetry

287 are not good candidates for the prediction of high levels of growth stresses, but they help to predict

288 a higher asymmetry of these stresses.

\section{Dendrometrical parameters and growth stress}

Slenderness $(H / D B H)$ and crown surface $(C S)$ seem to be the best predictors of high or low growth stresses in old beech trees. A high ratio $H / D B H$ is clearly a factor that leads to increased growth stresses. This was also shown by previous studies (Polge 1981; Ferrand 1982; Saurat and Gueneau 1976). On the contrary, big crowns (and big diameters $D B H$ ) are favourable factors that in general lead to a moderate to low growth stress level.

295 Using classes of values for crown surface and tree slenderness (Online Resource 6) shows that all 296 GSI parameters always decreases when CS increases and the reverse is true for H/DBH.

297 But no more than $10 \%$ of GSI variability is explained by $H / D B H$ and crown dimension. On one hand there are differences between trees for the basic level of growth stress without reaction wood 
299 (see variations in Min GSI). On the other hand, Max GSI controls the value of Mean and Max-Min

300 GSI, where Max GSI is well linked to the occurrence of tension wood produced by the tree. Not

301 every tree in each stand was subjected to such reaction phases, and the level of reaction is

302 therefore not the same. This explains the high variability in growth stress due to individual tree

303 history, apart from general trends linked to forest management.

304 Part of the negative correlations between growth stress indicators and both, $D B H$ and crown

305 surface can be linked to the very high negative correlation between slenderness and these 306 parameters in our stands.

\section{Forest management and growth stress.}

308 Stand effect is highly significant both on growth stress indicators and dendrometrical parameters.

309 We can hypothesize that stand effect is strongly linked to forest management, e.g. related to mean 310 number of adult trees per hectare. Upon the assumption of a closed canopy by the gathering of all 311 crowns, the mean crown surface per tree is smaller for a great number of trees per hectare.

312 Crown surface has a very high level of correlation with $D B H$ (positive) and slenderness (negative), 313 but not with total height, the latter one is being known to depend more on stand age and soil 314 fertility than on forest management. It has also very significant correlation with all growth stress 315 indicators (Table 4).

316 Looking at the implications to forest management, it can be deduced that low spacing of trees 317 induce small mean crown surface, small mean $D B H$ and high slenderness at a given age. Thus 318 higher spacing of trees seems to be a good solution to lower the level of growth stress in high 319 forest beech stands, which confirms findings by (Polge 1981 and Ferrand 1982).

\section{Conclusion}

321 Most of the trees have an uneven distribution of growth stress around the trunk but geometry of 322 the trunk itself was not a good predictor of growth stress level. Trunk inclination is not globally 323 correlated to growth stress indicators. For trunk inclinations higher than $2.5 \%$, it appears a 
significant drop of maximum, minimum and mean GSI values although the difference between tensile and opposite side is kept more or less constant.

326 High slenderness ratio between total height of the tree and trunk diameter at breast height $327(H / D B H)$, is the best predictor of high level of growth stress, although variations in $\mathrm{H} / \mathrm{DBH}$ explain only $10 \%$ of mean and maximum growth stress variability. On the contrary, large crown surface is the best predictor of low level of growth stress. These two descriptors are strongly negatively correlated.

331 Thus large tree spacing is a good solution to lower the risk of high levels of growth stress in 332 Beech, as it appears through the mean values per stand, and as was previously stated by various 333 authors.

\section{(vii) Acknowledgments}

336 The authors would like to thank all the people that have been involved in the huge campaign of data measurements and all the people that have collaborated to this large European project. They

338 also would like to thank their colleague Tancrède Alméras who has helped a lot to conduct 339 statistical data analyses of this paper.

\section{$340 \quad$ (viii) Funding}

341 This work was performed in the frame of the contract FAIR-98-3606 "Stresses in beech"

342 supported by the European Commission. (Becker and Beimgraben 2001).

\section{(ix) References}


344 Alméras T, Fournier M (2009) Biomechanical design and long-term stability of trees:

345 Morphological and wood traits involved in the balance between weight increase and the

346 gravitropic reaction. Journal of Theoretical Biology 256: 370-381. doi:

347 http://dx.doi.org/10.1016/j.jtbi.2008.10.011

348 Alméras T, Thibaut A, Gril J (2005) Effect of circumferential heterogeneity of wood maturation

349 strain, modulus of elasticity and radial growth on the regulation of stem orientation in trees. Trees

350 19: 457-467. doi: 10.1007/s00468-005-0407-6

351 Alvarez-Gonzalez J G, Zingg A, Gadow KV (2010) Estimating growth in beech forests: a study

352 based on long term experiments in Switzerland. Ann. For. Sci. 67: 307 . doi:

353 http://dx.doi.org/10.1051/forest/2009113

354 Archer RR (1986) Growth Stresses and Strains in Trees. Springer-Verlag, Berlin, pp 1-249

355 Baillères H (1994) Précontraintes de Croissance et Propriétés Mécanophysiques

356 de Clones d'Eucalyptus (Pointe Noire - Congo): Hétérogénéités, Corrélations et Interprétations

357 Histologiques. Thèse Université Bordeaux I, 162 p.

358 Barbacci, A., Constant, T., Magnenet, V. Nepveu, G., Fournier, M., 2009. Experimental analysis

359 of the formation of tension wood induced by gravity for three mature beech trees on a 25 years

360 duration. In 6th Plant Biomechanics Conference. pp. 306-314.

361 Becker G, Beimgraben T (2001) Occurrence and relevance of growth stresses in Beech (Fagus

362 sylvatica L.) in Central Europe, Final Report of FAIR-project CT 98-3606, Coordinator Prof. G.

363 Becker, Institut für Forstbenutzung und forstliche Arbeitwissenschaft, Albert-Ludwigs Universität,

364 Freiburg, Germany, 323 p.

365 Coutand C, Fournier M, Moulia B (2007) The Gravitropic Response of Poplar Trunks: Key Roles

366 of Prestressed Wood Regulation and the Relative Kinetics of Cambial Growth versus Wood

367 Maturation. Plant Physiology 144: 1166-1180. doi: http://dx.doi.org/10.1104/pp.106.088153

368 Ferrand JC (1982) Etude des contraintes de croissance. Deuxième partie : variabilité en forêt des

369 contraintes de croissance du hêtre (Fagus sylvatica L.). Ann. Sci. For. 39 : 187-218

370 Fournier M, Chanson B, Thibaut B, Guitard D (1991) Mécanique de l'arbre sur pied: modélisation

371 d'une structure en croissance soumise à des chargements permanents, évolutifs. Partie 2: 
application à l'analyse tridimensionnelle des contraintes de maturation. Ann. Sci. For. 48: 527546.

Fournier M, Baillères H, Chanson B (1994a) Tree biomechanics: growth, cumulative prestresses and re-orientations. Biomimetics 2: 229-251

Fournier M, Chanson B, Thibaut B, Guitard D (1994b) Mesure des déformations résiduelles de croissance à la surface des arbres, en relation avec leur morphologie. Observations sur différentes espèces. Ann. Sci. For. 51: 249-266. doi: http://dx.doi.org/10.1051/forest:19940305 Jullien D, Gril J (1996) Mesure des déformations bloquées dans un disque de bois vert. Méthode de la fermeture. Ann. Sci. For. 53: 955-966. doi: http://dx.doi.org/10.1051/forest:19960504 Jullien D, Gril J (2008) Growth strain assessment at the periphery of small-diameter trees using the two-grooves method: influence of operating parameters estimated by numerical simulations. Wood Sci. Tech. 42: 551-565. doi: 10.1007/s00226-008-0202-9

Jourez B, Avella-Shaw T (2003) Effect of gravitational stimulus duration on tension wood formation in young stems of poplar (Populus euramericana cv 'Ghoy'). Ann. Sci. For. 60: 31-41. doi: http://dx.doi.org/10.1051/forest:2002071

Knoke T, Stang S, Remler N, Seifert T (2006) Ranking the importance of quality variables for the price of high quality beech timber (Fagus sylvatica L.). Ann. For. Sci. 63: 399-413. doi: http://dx.doi.org/10.1051/forest:2006020

Kubler H (1987) Growth stresses in trees and related wood properties. Forestry Abstracts 48: 131189

Liu S, Loup C, Gril J, Dumonceaud O, Thibaut A, and Thibaut B (2005) Studies on European beech (Fagus sylvatica L.). Part 1: Variations of wood color parameters. Ann. For. Sci. 62: 625632. doi: http://dx.doi.org/10.1051/forest:2005063

Moulia B, Fournier M (2009) The power and control of gravitropic movements in plants: a biomechanical and systems biology view. Journal of Experimental Botany, 60 : 461-486. doi: $10.1093 / \mathrm{jxb} / \mathrm{ern} 341$

Polge H (1981) Influence des éclaircies sur les contraintes de croissance du hêtre. Ann. Sci. For. $38: 407-423$ 
400 Saurat J, Gueneau P (1976) Growth stresses in beech. Wood Sci. Tech. 10: 111-123. doi:

$401 \quad 10.1007 / \mathrm{BF} 00416786$

402 Thibaut B, Gril J (2003) Growth stresses. Chapter 6: 137-156; Wood quality and its biological 403 basis; Barnett J.R. \& Jeronimidis G. Ed, CRC Press

404 Wilson BF, Archer RR (1979) Tree design: some biological solutions to mechanical problems.

405 Bioscience 29: 293-298

406 Wilson BF, Gartner BL (1996) Lean in red alder (Alnus rubra): growth stress, tension wood, and

407 righting response. Can. J. For. Res. 26:1951-1956. doi: 10.1139/x26-220

408 Yang JL, Baillères H, Okuyama T, Muneri A, Downes G (2005) Measurement methods for

409 longitudinal surface strain in trees: a review Australian Forestry 68: 34-43

$410 \quad(\mathbf{x})$ Tables

\begin{tabular}{|c|c|c|c|c|c|c|c|}
\hline Stand & $\mathrm{Nb}$ & Crown & Crown & Trunk & Trunk & Trunk & Trunk \\
\hline $\mathrm{Aa}$ & 45 & 14 & 31 & 20 & 6 & 7 & 12 \\
\hline $\mathrm{Ab}$ & 49 & 17 & 32 & 35 & 6 & 7 & 1 \\
\hline $\mathrm{Dk}$ & 50 & 34 & 16 & 27 & 7 & 6 & 10 \\
\hline $\mathrm{Fa}$ & 50 & 14 & 36 & 32 & 4 & 11 & 3 \\
\hline $\mathrm{Fb}$ & 50 & 20 & 30 & 27 & 3 & 12 & 8 \\
\hline $\mathrm{Fc}$ & 50 & 28 & 22 & 32 & 1 & 13 & 4 \\
\hline $\mathrm{G}$ & 46 & 24 & 22 & 22 & 6 & 13 & 5 \\
\hline $\mathrm{Sa}$ & 50 & 19 & 31 & 19 & 15 & 4 & 12 \\
\hline $\mathrm{Sb}$ & 50 & 24 & 26 & 37 & 0 & 8 & 5 \\
\hline Total & 440 & 194 & 246 & 251 & 48 & 81 & 60 \\
\hline
\end{tabular}

Table 1: Repartition of trees of each stand in each morphological category of crown (sym : symmetric; asym:

asymmetric) and trunk (T1: straight, T2: curved at base, T3: with one big curve; T4: sinuous with more than one curve) 


\begin{tabular}{|l|c|c|c|c|c|c|c|c|c|c|}
\hline & GSI Min & $\begin{array}{c}\text { GSI } \\
\text { Max }\end{array}$ & $\begin{array}{c}\text { GSI } \\
\text { Range }\end{array}$ & $\begin{array}{c}\text { GSI } \\
\text { Mean }\end{array}$ & DBH & H & H/DBH & CS & TI & CE \\
\hline & $\mu \mathrm{m}$ & $\mu \mathrm{m}$ & $\mu \mathrm{m}$ & $\mu \mathrm{m}$ & $\mathrm{cm}$ & $\mathrm{m}$ & $\mathrm{cm} / \mathrm{m}$ & $\mathrm{m}^{2}$ & $\%$ & $\mathrm{~m}$ \\
\hline Mean & 23,9 & 122 & 97,1 & 62,3 & 60,2 & 33,3 & 56,3 & 83,7 & 4,0 & 1,8 \\
\hline Mediar & 21,0 & 121 & 95,5 & 59,4 & 57,9 & 33,5 & 56,6 & 68,7 & 3,0 & 1,6 \\
\hline Sd & 15,6 & 49,8 & 45,0 & 25,6 & 10,6 & 4,1 & 9,1 & 54,9 & 4,0 & 1,1 \\
\hline Min & - & 21,0 & 16,0 & 12,3 & 42,7 & 21,0 & 34,2 & 14,0 & - & 0,1 \\
\hline Max & 114 & 295 & 269 & 155 & 113 & 44,0 & 83,2 & 439 & 23,5 & 6,6 \\
\hline $\mathrm{Nb}$ & 440 & 440 & 440 & 440 & 440 & 440 & 440 & 440 & 440 & 440 \\
\hline
\end{tabular}

414

Table 2: General results at tree level (440 trees)

GSI growth stress indicator; DBH diameter at breast height;

$\mathrm{H}$ height; CS crown surface; TI trunk inclination; CE crown eccentricity

\begin{tabular}{|c|c|c|c|c|c|c|c|c|c|}
\hline $\begin{array}{l}\text { GSI } \\
\text { Min }\end{array}$ & $\begin{array}{l}\text { GSI } \\
\text { Max }\end{array}$ & $\begin{array}{c}\text { GSI } \\
\text { Range }\end{array}$ & $\begin{array}{c}\text { GSI } \\
\text { Mean }\end{array}$ & $\mathrm{DBH}$ & $\mathrm{H}$ & $\mathrm{H} / \mathrm{DBH}$ & CS & $\mathrm{TI}$ & $\mathrm{CE}$ \\
\hline$\mu \mathrm{m}$ & $\mu \mathrm{m}$ & $\mu \mathrm{m}$ & $\mu \mathrm{m}$ & $\mathrm{cm}$ & $\mathrm{m}$ & $\mathrm{m} / \mathrm{cm}$ & $\mathrm{m}^{2}$ & $\%$ & $\mathrm{~m}$ \\
\hline \multirow[t]{3}{*}{$* * *$} & $* * *$ & $* * *$ & $* * *$ & $* * *$ & $* * *$ & $* * *$ & $* * *$ & $* * *$ & $* * *$ \\
\hline & & & & & & & & $* * *$ & \\
\hline & & $* *$ & & $* * *$ & $*$ & $* *$ & $* * *$ & $* * *$ & $* * *$ \\
\hline
\end{tabular}

Table 3: Variance analysis for stand, trunk and crown type effects (440 trees)

GSI growth stress indicator; DBH diameter at breast height

$\mathrm{H}$ height; $\mathrm{CS}$ crown surface; $\mathrm{TI}$ trunk inclination; CE crown eccentricity

\begin{tabular}{|c|c|c|c|c|c|c|c|c|c|c|}
\hline & Min & Max & Range & Mean & $\mathrm{DBH}$ & $\mathrm{H}$ & $\mathrm{H} / \mathrm{DBH}$ & CS & TI \% & CE m \\
\hline Min & 1 & $* * *$ & & $* * *$ & & $* *$ & $* * *$ & $* * *$ & $* * *$ & $* *$ \\
\hline Max & 0,492 & 1 & $* * *$ & $* * *$ & $* * *$ & $*$ & $* * *$ & $* * *$ & & \\
\hline Range & 0,145 & 0,931 & 1 & $* * *$ & $* * *$ & & $* * *$ & $* * *$ & & \\
\hline Mean & 0,779 & 0,854 & 0,647 & 1 & $* *$ & $* * *$ & $* * *$ & $* * *$ & $* * *$ & $* *$ \\
\hline $\mathrm{DBH}$ & $-0,110$ & $-0,247$ & $-0,233$ & $-0,177$ & 1 & $* * *$ & $* * *$ & $* * *$ & & \\
\hline $\mathrm{H}$ & 0,197 & 0,136 & 0,075 & 0,208 & 0,359 & 1 & $* * *$ & & $* * *$ & \\
\hline $\mathrm{H} / \mathrm{DBH}$ & 0,246 & 0,323 & 0,266 & 0,313 & $-0,666$ & 0,437 & 1 & $* * *$ & & $*$ \\
\hline CS & $-0,236$ & $-0,272$ & $-0,210$ & $-0,253$ & 0,656 & 0,123 & $-0,498$ & 1 & & $*$ \\
\hline TI \% & $-0,295$ & $-0,063$ & 0,051 & $-0,223$ & $-0,087$ & $-0,209$ & $-0,092$ & 0,070 & 1 & $* * *$ \\
\hline CE $m$ & $-0,196$ & $-0,073$ & $-0,005$ & $-0,177$ & 0,063 & $-0,075$ & $-0,140$ & 0,149 & 0,440 & 1 \\
\hline
\end{tabular}

Table 4 Correlation between parameters for the straight trees (type 1, 251 trees)

$*, * *, * * *$ respectively significant at $5 \%, 1 \%$ and $0.1 \%$ level

Min, Max, Range=Max-Min, Mean: GSI growth stress indicators eccentricity 
418 Fig. 1 Compressive support stress distribution at the bottom of a column. Left: built in one

419 operation, then erected. Right: built by successive additions of elements glued to the previous ones

420 Fig. 2 Flexure support stress distribution for horizontal beam/branch anchored at one end, subject

421 to gravity. Dotted line: stress distribution for a man-made cylindrical beam.Continuous line:

422 stress distribution for a growing stem with constant allometry: $H \propto R^{2 / 3}$

423 Fig. 3 Stress distribution at tree base level for a beech "equivalent tree" of characteristics:

424 Diameter 50cm, Height 30m, Trunk inclination 5\%, constant peripheral maturation stress: 9,64

425 MPa. Flex: Flexure support stress; Comp: Compressive support stress; Mat: Maturation stress

426 Total: Growth stress $=$ Flexure support stress + Compressive support stress + Maturation stress

427 Fig. 4 Distribution of GSI values in relation to the cardinal points. In this example (tree G44) the 428 tension wood zone stretches fom the North to the East

429 Fig. 5 Distribution of tree Growth Stress Indicator (GSI) parameters

430 Fig. 6 Relationship between Tension-Opposite Growth Stress Indicator and Max-Min Growth $431 \quad$ Stress Indicator for 390 trees

432 Fig. 7 Relationship between maximum growth stress indicator (GSI Max) and tree slenderness $433(H / D B H)$ for the straight trees

434 Fig. 8 Mean value in each stand of the 8 measurements sorted from the smallest to the highest per 435 tree. OW: opposite wood; TW: tension wood; Stands: $A a, A b, D k, F a, F b, F c, G, S a, S b$

$436 \quad$ (xii) figures 


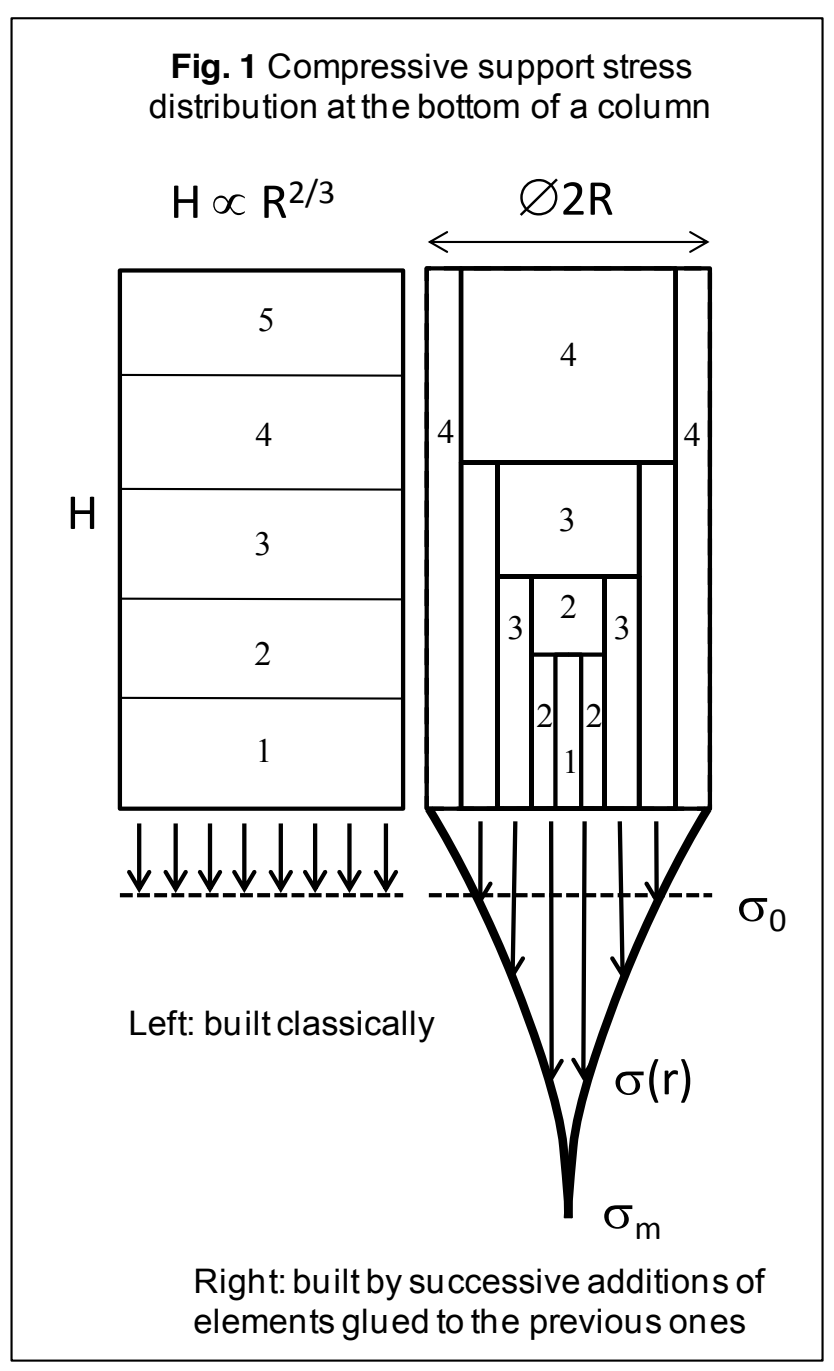




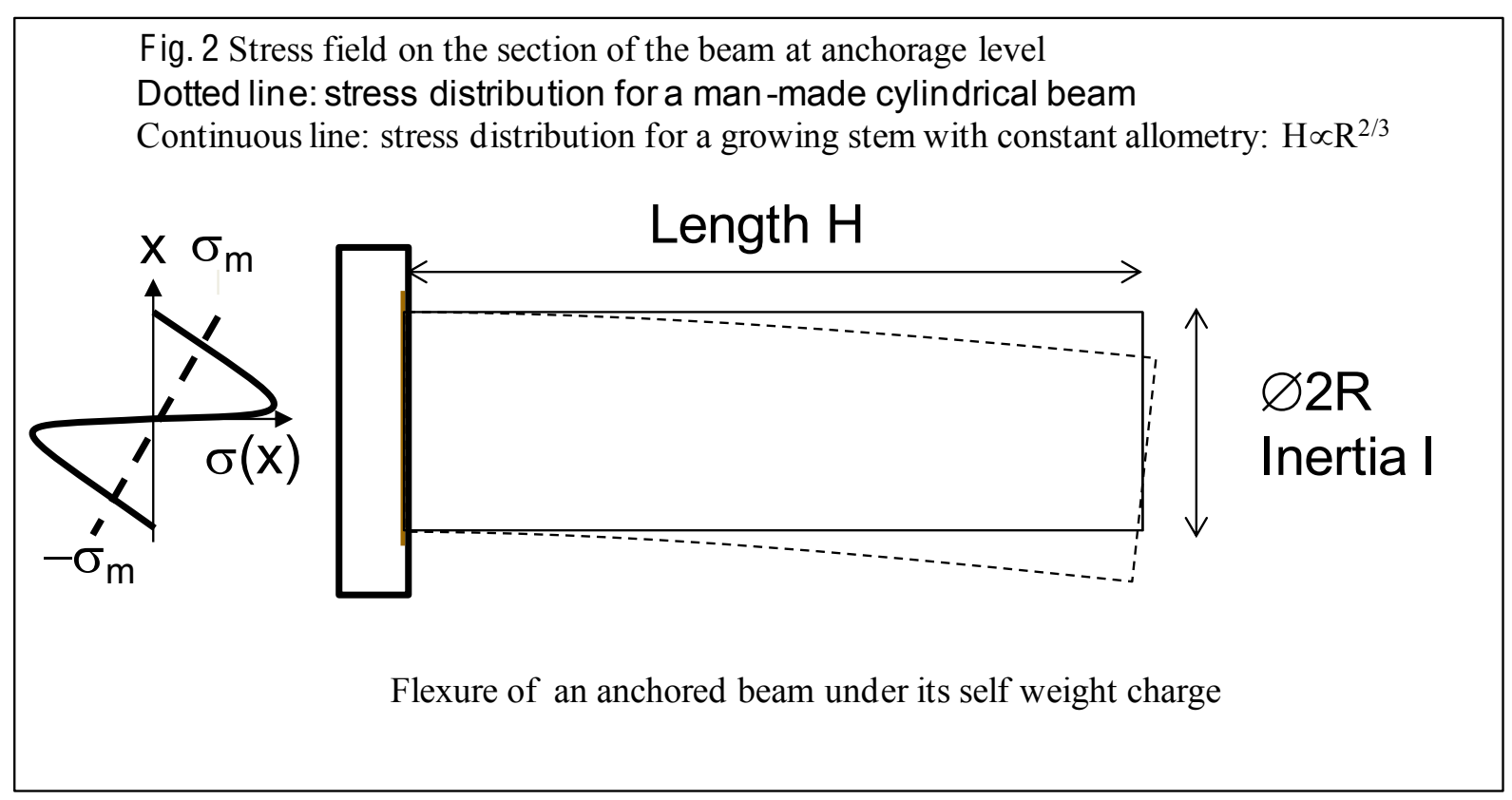




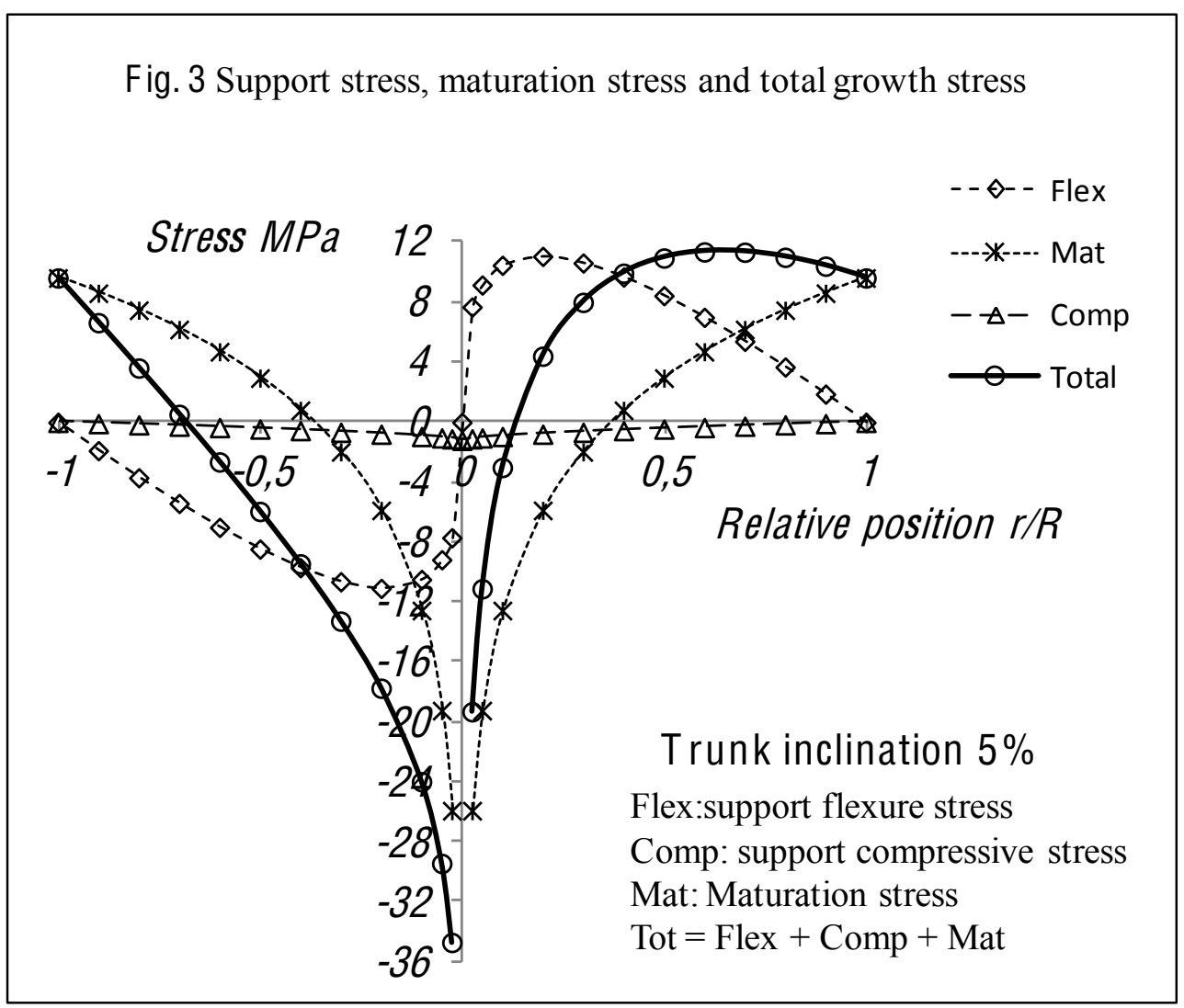




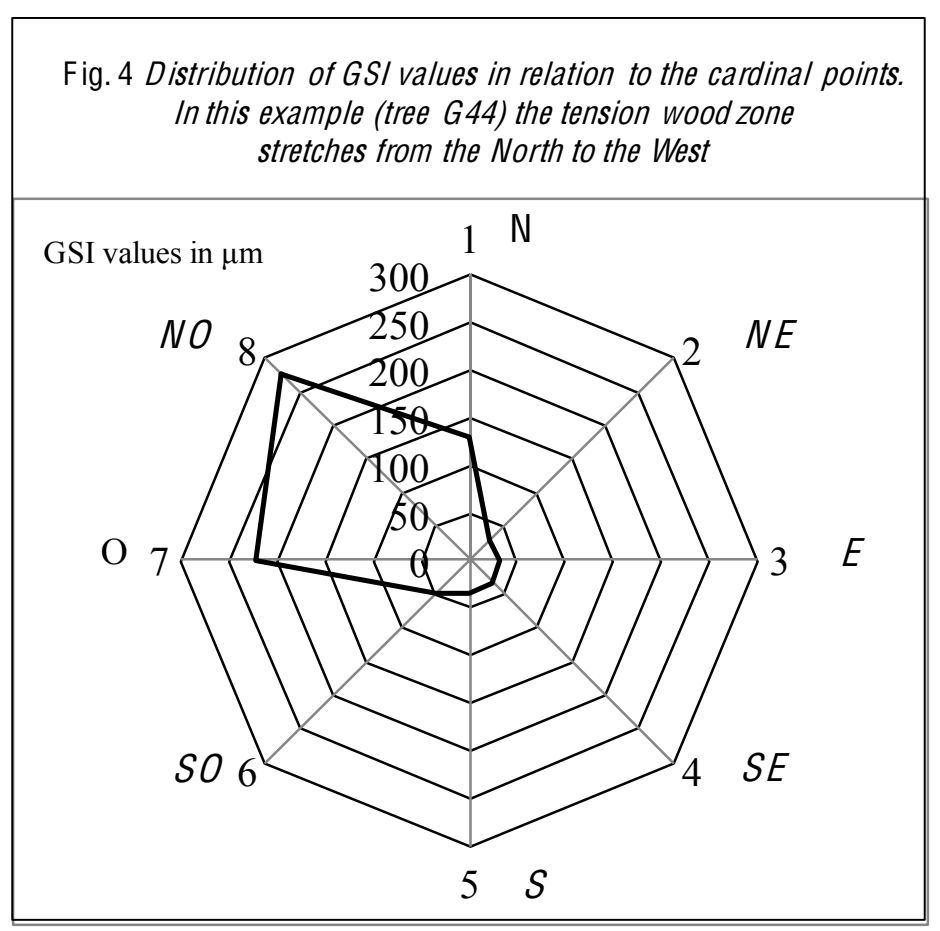




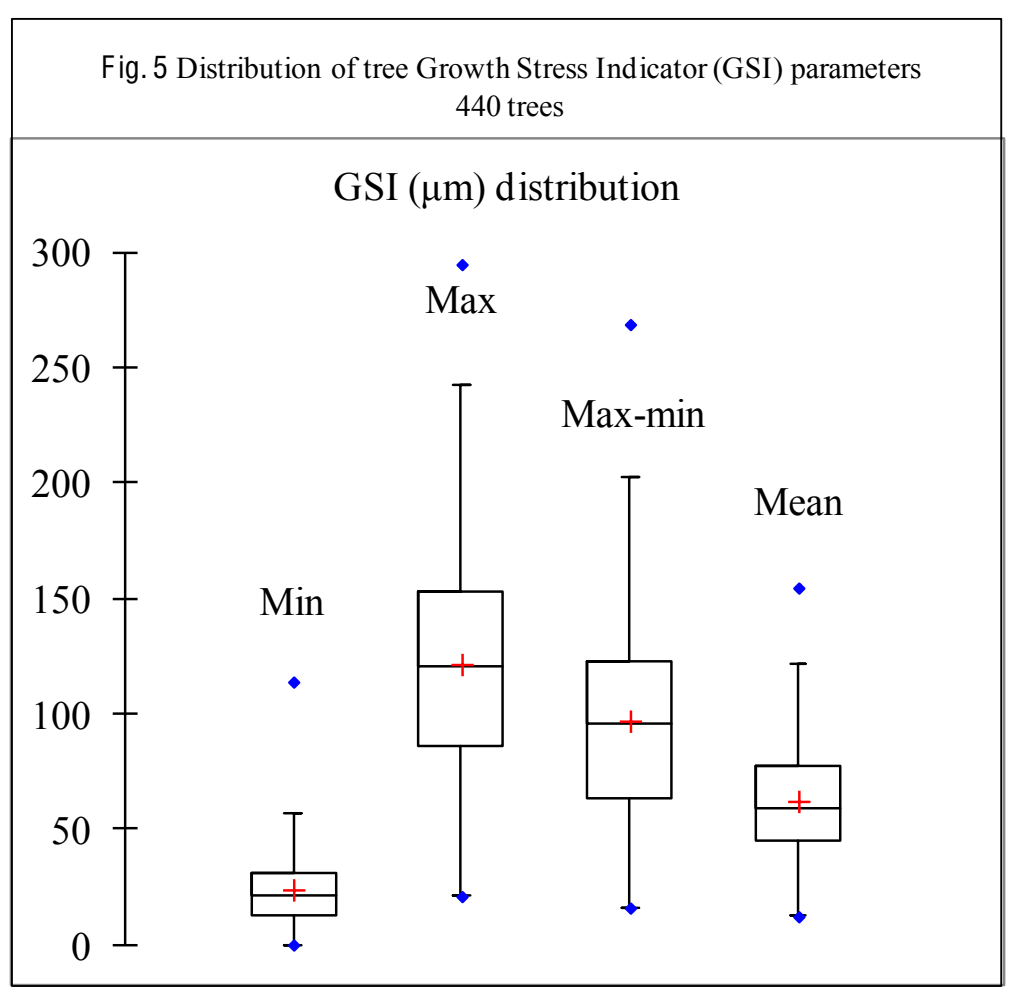




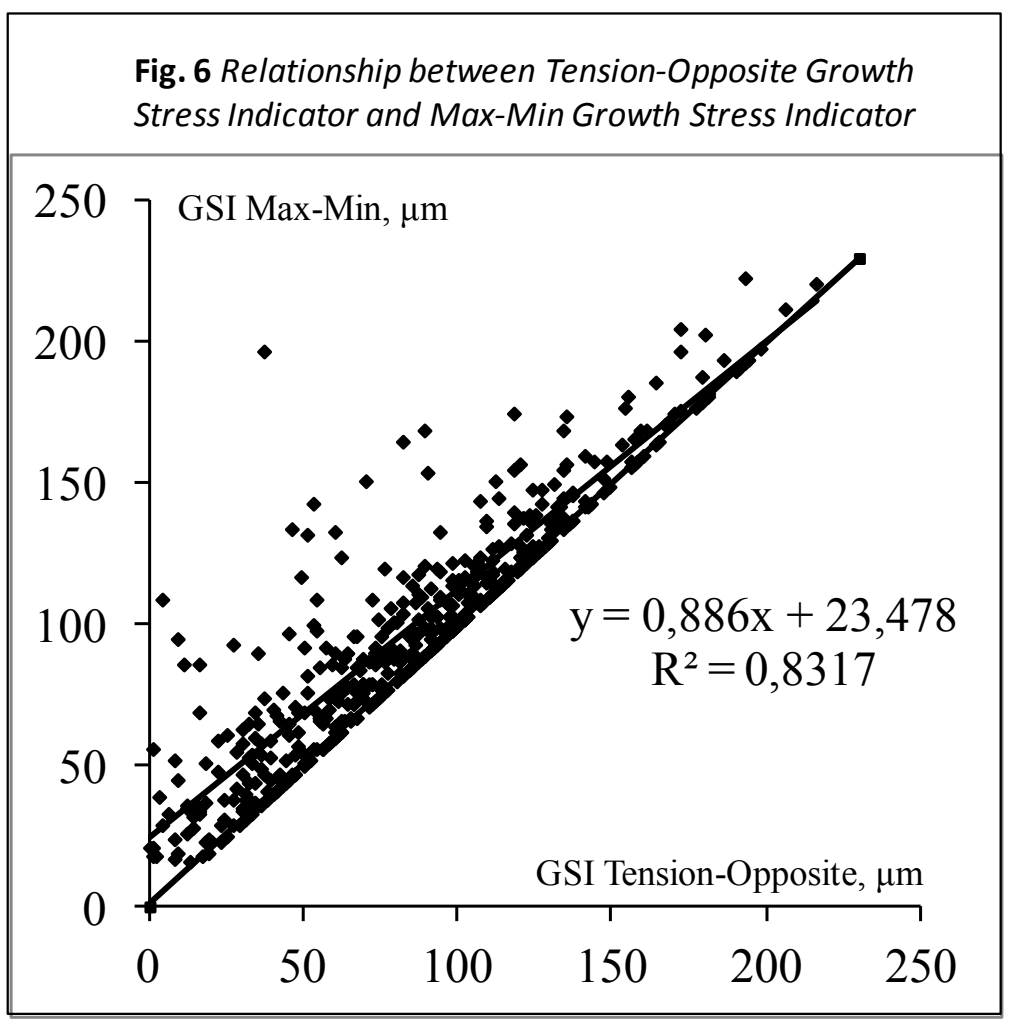




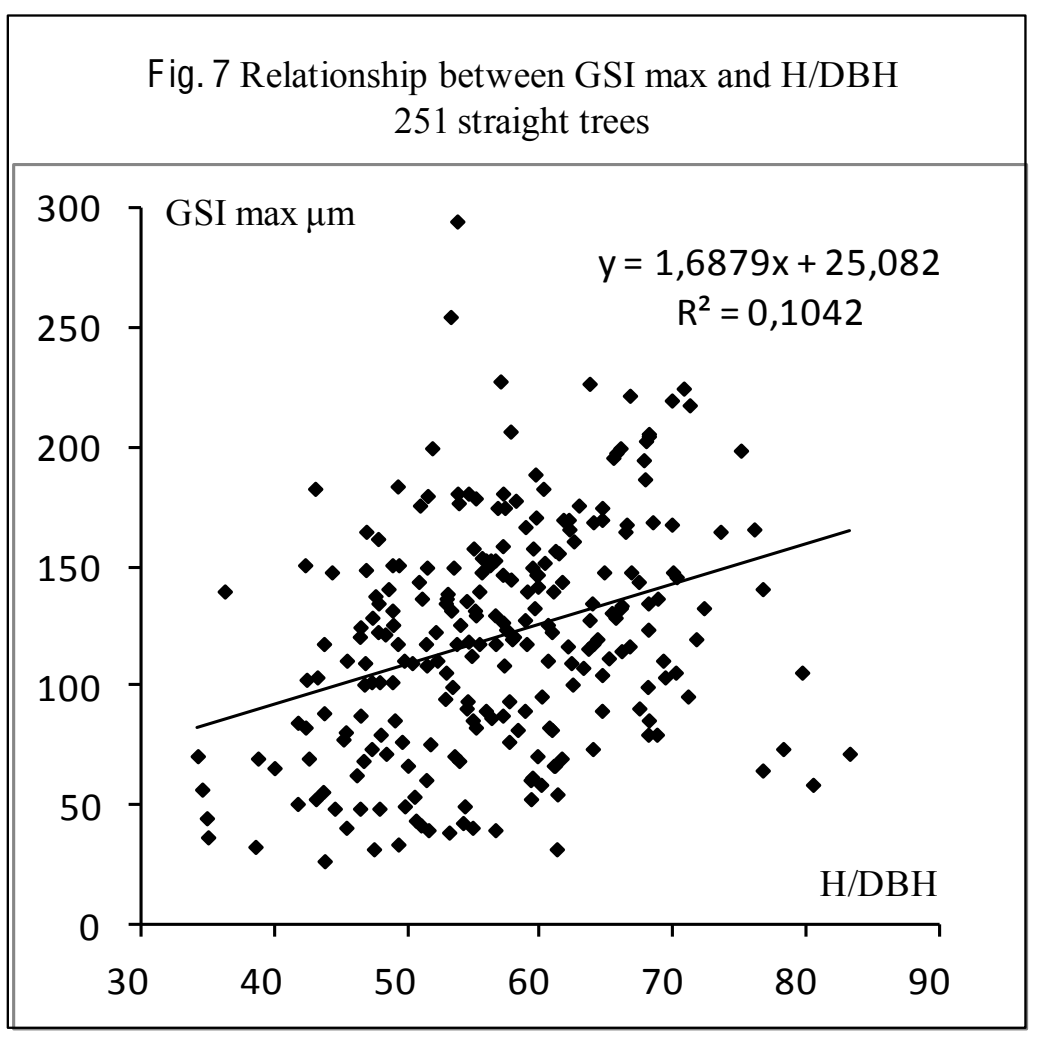




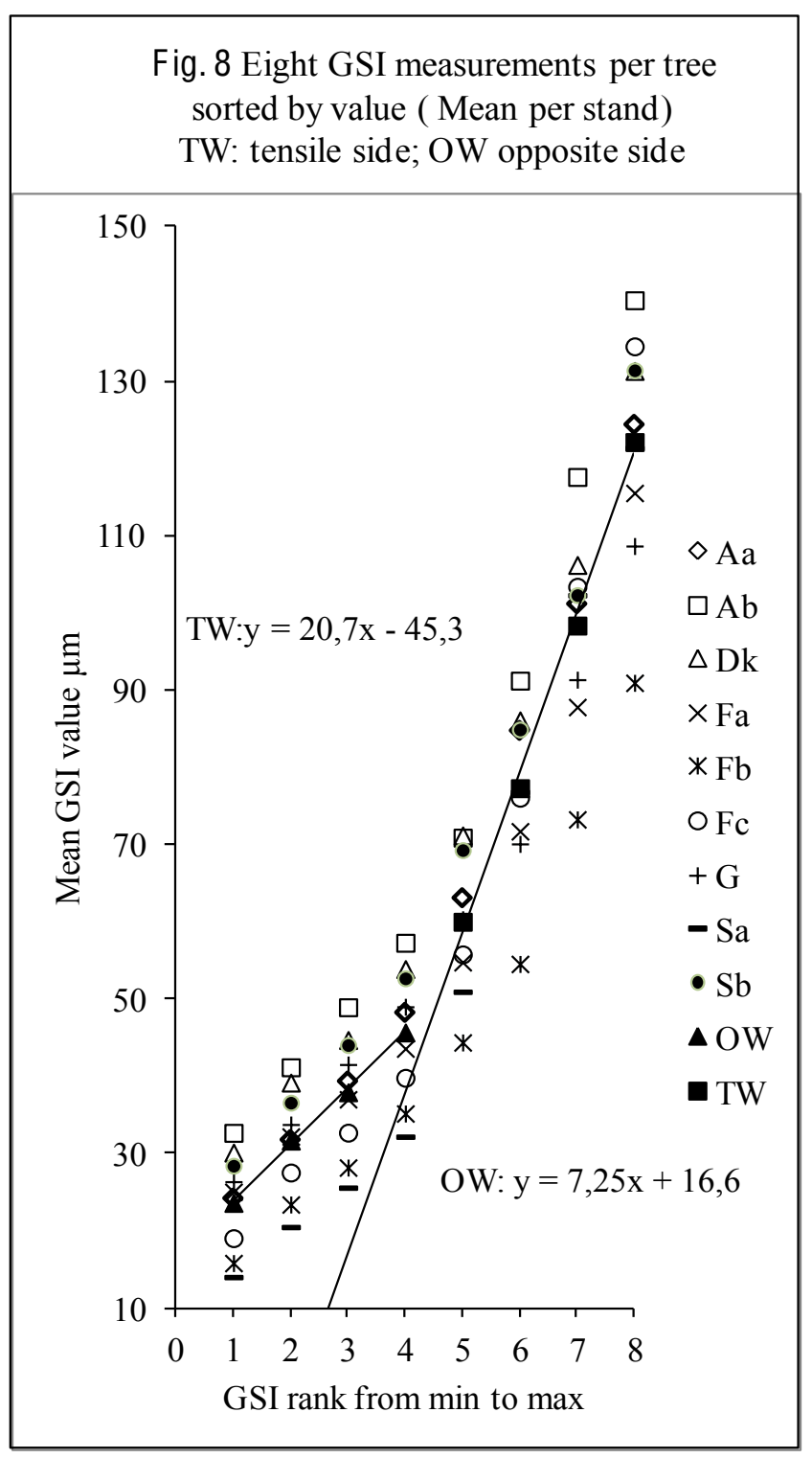

